\title{
Model Multisensori: Solusi Stimulasi Literasi Anak Prasekolah
}

\author{
Lisnawati Ruhaena ${ }^{1}$ \\ Fakultas Psikologi \\ Universitas Muhammadiyah Surakarta
}

\begin{abstract}
This research aimed to develop a model of literacy stimulation for preschool children in order to meet their needs and to overcome parents' problems in stimulating literacy in their children at home. The data of children's needs and parents' problem were obtained from questionnaires and focus group discussion. The questionnaires were filled by 75 mothers whose children aged 3-5 years old in Surakarta. Then, 26 of them attended focused group discussion. The data obtained showed that there was a problem in these children's early literacy development. Most of them were lack of interest in literacy activities and most of the parents were unable to attract their children's attention and interest. The problem faced by the parents was the lack of skill in selecting and doing literacy activities in accordance with their children's needs. A multisensory model was designed to improve pre-school children's interest in early development of literacy and to increase parents' skill in stimulating their children's interest.
\end{abstract}

Keywords: multisensory model, early literacy, preschool children

Abstrak. Penelitian ini bertujuan mengembangkan model stimulasi literasi anak prasekolah untuk memenuhi kebutuhan anak dan mengatasi masalah orang tua dalam upayanya melakukan stimulasi literasi anak prasekolah di rumah. Data kebutuhan anak dan masalah orang tua diperoleh dari kuesioner dan diskusi kelompok terarah. Kuesioner diisi oleh 75 ibu yang memiliki anak usia 3-5 tahun, anggota posyandu dan tinggal di kota Surakarta. Selanjutnya 26 orang dari 75 orang ibu tersebut, mengikuti diskusi kelompok terfokus. Data yang dikumpulkan menunjukkan bahwa anak memiliki kebutuhan untuk mendapat stimulasi literasi yang menarik perhatian dan menggugah minat mereka terhadap kegiatan literasi. Masalah yang dihadapi orang tua adalah kurangnya keterampilan untuk memilih dan melakukan aktivitas literasi anak yang sesuai kebutuhan anaknya. Oleh karena itu dikembangkan model stimulasi yang bersifat multisensoris (audio, visual, dan kinestetik) agar perhatian dan minat anak meningkat.

Kata kunci: model multisensori, kemampuan literasi anak prasekolah

Undang-Undang Nomor 20 Tahun 2003 menyatakan bahwa pendidikan nasional berfungsi mencerdaskan kehidupan bangsa, untuk mencapainya diselenggarakan pendidikan mulai dari

\footnotetext{
${ }^{1}$ Korespondensi mengenai artikel ini dapat melalui: lisnawati.ruhaena@ums.ac.id atau lisnawati.purtojo@ gmail.com
}

pendidikan anak usia dini (PAUD) sampai dengan perguruan tinggi (Renstra Kemendiknas 2010-2014). Pada tataran PAUD, pendidikan difokuskan untuk mematangkan anak didik secara emosi, sosial, dan kognitif agar dapat mengikuti proses belajar di sekolah dasar. Pendidikan anak usia dini yang bersifat formal adalah 
sekolah taman kanak-kanak (TK) dan taman bermain, sedangkan yang bersifat informal adalah pendidikan dalam keluarga atau masyarakat. Pada kenyataannya saat ini yang lebih berfungsi adalah PAUD secara formal, sedangkan yang informal belum terarah.

Pendidikan anak usia dini erat kaitannya dengan pengembangan literasi anak prasekolah. Kemampuan literasi anak prasekolah menjadi prediktor bagi kemampuan literasi anak di kelas IV (Ko \& Chan, 2009). Hasil penelitian PIRLS 2006 di 45 negara yang diteliti menunjukkan bahwa anak yang berasal dari keluarga yang menstimulasi kemampuan literasi anak sejak dini, memiliki kemampuan literasi yang lebih tinggi (Mullis, Martin, Kennedy, \& Foy, 2007). Kemampuan literasi anak prasekolah yang baik membantu anak untuk lebih mudah belajar membaca dan meningkatkan tingkat kesuksesan anak di sekolah (Senechal \& LeFreve, 2002). Hasil metaanalisis yang dilakukan oleh National Early Literacy Panel (NELP) pada tahun 2008 menunjukkan bahwa kemampuan literasi anak prasekolah memprediksi kemampuan literasi selanjutnya pada tingkat sedang sampai tinggi.

Pendidikan informal anak usia dini dalam keluarga atau masyarakat sebenarnya sangat potensial untuk difungsikan dengan optimal dalam pengembangan literasi anak. Orangtua sebagai guru pertama bagi anak memiliki waktu dan proses interaksi lebih banyak dibandingkan guru dan orang lainnya untuk membimbing anak menguasai kemampuan literasi anak prasekolah. Namun demikian hal ini kurang didukung oleh pengetahuan dan kemampuan orangtua. Selain itu juga gerakan permerintah ataupun program intervensi pemberdayaan keluarga dalam membimbing anak prasekolah menguasai kemampuan literasi anak prasekolah (early literacy) di Indonesia belum muncul seperti negara lain. Amerika menyelenggarakan program yang disebut Early Head Start dan Head Star, di Israel dikenal Home Instruction for Parents of Preschool Youngsters (HIPPY), di Malaysia dikenal program Nury. Untuk itu dibutuhkan sebuah model stimulasi yang teruji efektif secara empiris di Indonesia untuk mengembangkan kemampuan literasi anak sejak dini.

Stimulasi kemampuan literasi anak prasekolah dapat dilakukan di rumah melalui aktivitas literasi orangtua dengan anak di tengah kegiatan sehari-hari. Penelitian di negara maju menunjukkan bahwa aktivitas literasi orangtua dan anak di rumah merupakan prediktor bagi perkembangan kemampuan literasi anak prasekolah (Aram, Most, \& Mayafit, 2006; Burgess, Hecht, \& Lonigan, 2002; Levy, Gong, Hessels, Evans, \& Jared, 2006; Raikes, Alexander Pan, Luze, TamisLeMonda, Brooks-Gunn, Constantine, Banks Tarullo, Abigail Raikes, \& Rodriguez., 2006; Stephenson, Parrila, Georgiou, \& Kirby, 2008). Penelitian di Indonesia yang penulis lakukan di Kota Surakarta (Ruhaena, Kumara, Adiyanti, Helmi, 2014), menunjukkan bahwa aktivitas literasi orang tua dan anak tidak menjadi prediktor kemampuan literasi anak prasekolah. Perbedaan ini terjadi karena aktivitas literasi yang dilakukan di Indonesia lebih banyak mengajar teks melalui menghafal huruf dan mengeja kata. Cara ini terlalu tekstual dengan pendekatan kognitif yang menuntut konsentrasi sehingga kurang menyenangkan untuk anak. Hal ini berbeda dengan aktivitas literasi yang dilakukan di negara maju seperti Amerika, Inggris, dan Australia yang lebih kontekstual dan aplikatif dalam kegiatan seharihari yang natural seperti membaca buku 
cerita dan bermain literasi yang membuat anak tertarik dan termotivasi.

Penelitian lain menunjukkan bahwa kegiatan literasi yang dapat menjadi prediktor adalah yang bersifat aktif melakukan eksplorasi dan berpartisipasi (Burgess dkk., 2002; Levy, Gong, Hessels, Evans, \& Jared, 2006). Aktivitas literasi menurut Brooker (2011) harus merupakan aktivitas bermain. Bermain ini dapat berupa mengajak anak bercakap-cakap dan memberikan verbal scaffolding (Dieterich, Assel, Swank, Smith, \& Landry, 2006); Neumen, Hood, \& Neumen, 2009), bermain terkait huruf, dan kata (Evans dkk., 2000; Roskos \& Christie, 2001; Stephenson, Parrila, Georgiou, \& Kirby, 2008), bermain peran (Roskos, Christie, Widman, \& Holding, 2010) mengajari pengetahuan tulisan, mengenalkan bunyi huruf, nama alfabet (Senechal \& LeFevre, 2002), mengajari anak menulis (Fisher, 2010; Graham, Harris, \& Fink, 2000), menggambar (Kendrick \& Mckay, 2004). Selain itu yang lebih penting adalah aktivitas membaca buku cerita. Bahkan membaca buku secara interaktif menurut DeBruin-Parecki (2009) merupakan hal penting dalam pengembangan kemampuan literasi anak prasekolah. Lingkungan sekitar juga menyediakan tulisan yang dapat difungsikan untuk meningkatkan kemampuan literasi anak prasekolah (Neumann, Hood, \& Ford, 2012; dan Neumann, Hood, \& Ford, 2013).

Temuan dari penelitian sebelumnya menunjukkan bahwa metode belajar yang aktif dan merangsang semua alat indera (multisensoris) lebih efektif bagi anak prasekolah karena sesuai dengan kebutuhan dan karakteristik psikologis anak (Ruhaena, 2008). Pendekatan multisensoris menciptakan suasana belajar sambil bermain dengan mengoptimalkan semua indera sensorik yang dimiliki anak (audio, visual dan kinestetik). Oleh kerena itu model multisensoris dapat menjadi solusi tepat dalam aktivitas literasi untuk menstimulasi kemampuan literasi anak prasekolah. Untuk mengembangkan model multisensoris, maka dilakukan penelitian ini.

Pendekatan multisensori dalam pengajaran literasi adalah sebuah proses belajar yang memanfaatkan sensori visual (penglihatan), auditori (pendengaran), dan kinestetik-taktil (gerakan, perabaan) untuk meningkatkan daya ingat dan proses belajar. Ketiga sensori dioptimalkan secara simultan dan saling mendukung sehingga anak dapat menyimpan bentuk, kode dan nama huruf lebih mudah. Dalam praktiknya anak diajarkan untuk mengkaitkan bunyi huruf dengan simbol/bentuk tertulis dan meraba, menuliskan bentuk hurufnya. Terjadi tiga proses yaitu melihat bentuk huruf, menyebutkan bunyinya, dan menuliskannya (Orton \& Gillingham, 2000). Terdapat beberapa alasan mengapa menggunakan pendekatan multisensori dalam pengembangan kemampuan literasi anak prasekolah. Maal (2004) menyatakan bahwa pendekatan ini meningkatkan keterlibatan anak karena rangsang yang masuk secara simultan terhadap sensori visual, auditif dan kinestetik tersimpan lebih dalam dan bertahan lama. Menurut Tiene (2000) mendengarkan informasi yang disajikan dengan input visual sangat efektif untuk membuat otak memprosesnya sekaligus. Farkas (2003) menunjukkan bahwa pendekatan ini meningkatkan sikap positif dan menghasilkan keterampilan. Dengan demikian dapat disimpulkan bahwa stimulasi sensori secara menyeluruh yang memanfaatkan semua modalitas sensorik meningkatkan keterlibatan anak dalam proses belajar, mengembangkan kapasitas dan potensi belajar yang dimiliki anak, merangsang efektivitas proses otak, mengembangkan 
sikap positif dan meningkatkan keterampilan yang diajarkan.

Model multisensori stimulasi literasi anak prasekolah merupakan rangsangan sedini mungkin yang terintegrasi dan mulai dilakukan di rumah oleh orangtua dalam situasi bermain yang menyenangkan tetapi merangsang semua sensoris anak. Dalam model ini orang tua di rumah dipandang bernilai strategis sebagai pendidik, aktivitas bermain bernilai strategis sebagai proses belajar, dan literasi sebagai materi belajar, serta pendekatan multisensori sebagai metode belajar yang efektif. Oleh karena itu penelitian ini bertujuan merancang model multisensori sebagai stimulasi kemampuan literasi anak sejak dini. Untuk mencapai tujuan itu dilakukan tahapan penelitian berupa: (1) survei aktivitas literasi orang tua-anak yang biasanya dilakukan di rumah, (2) identifikasi permasalahan apa yang menghambat pengembangan literasi, dan (3) merancang materi, media dan metode stimulasi dalam model multisensori.

\section{Metode}

Penelitian ini menggunakan metode riset dan pengembangan (research and development) yang mencakup analisis kebutuhan dan desain model. Penelitian ini merupakan tahapan pertama dari dua tahap yang direncanakan. Proses dalam penelitian ini dirinci sebagai berikut: (1) Analisis Kebutuhan. Pada tahap ini dilakukan analisis terhadap data yang dikumpulkan menggunakan kuesioner dan diskusi kelompok terarah. Kuesioner diisi oleh 75 orang ibu yang memiliki anak usia prasekolah berusia 3-5 tahun, diskusi terarah direncanakan diikuti oleh tiga kelompok yang masing-masing 10 orang, namun terdapat 4 orang yang tidak hadir sehingga peserta berjumlah 26 orang ibu.
Kelompok pertama terdiri dari 10 orang, kelompok kedua terdiri dari 9 orang dan kelompok ketiga terdiri dari 7 orang. Responden penelitian ini tinggal di kota Surakarta dengan mayoritas ibu rumah tangga dan penghasilan suami kurang dari dua juta rupiah. Data yang digali berupa cara orang tua menstimulasi dan membimbing anak menguasai literasi anak prasekolah dan masalah atau hambatan apa saja yang dihadapi oleh orang tua. Data ini kemudian dianalisis untuk menyimpulkan kebutuhan orang tua di lapangan sebagai dasar pembuatan draf model multisensori. Data yang dikumpulkan dari angket kemudian dihitung distribusi frekuensi dan persentasenya untuk menemukan respon yang menonjol dari pertanyaan yang diajukan. Respons yang menonjol ini memberikan informasi tentang pola umum perilaku responden terkait pengembangan literasi anak prasekolah. Data yang dikumpulkan dari diskusi kelompok terfokus dicatat secara deskriptif dengan alur keterkaitan sesuai pertanyaan saat proses diskusi. (2) Desain draf model multisensori. Berdasarkan hasil analisis kebutuhan dan tinjauan teoretis serta penelitian penulis sebelumnya maka kemudian disusun rancangan model multisensori yang diaplikasikan dalam bentuk aktivitas literasi sehari-hari untuk orang tua dan anak usia dini. Dalam model ini rancang pelatihan untuk ibu agar dapat melakukan aktivitas literasi di rumah, dan difasilitasi dengan pemberian media aktivitas literasi dalam sebuah paket berisi petunjuk dan mainan.

\section{H a s i 1}

\section{Hasil kuesioner}

Hasil kuesioner mencakup dua hal yaitu cara ibu menstimulasi kemampuan literasi anak prasekolah dan kegiatan yang dilakukan ibu bersama anaknya. Hasil 
yang pertama disajikan pada Tabel 1, dan hasil yang kedua disajikan pada Tabel 2.

Tabel 1

Stimulasi Kemampuan Literasi Anak Prasekolah

\begin{tabular}{llc}
\hline $\begin{array}{c}\text { Cara menstimulasi kemampuan literasi } \\
\text { anak prasekolah }\end{array}$ & \multicolumn{1}{c}{ Jawaban responden } & $\%$ \\
\hline Percakapan & mengajak anak bercakap-cakap & 66 \\
& berbicara untuk mengarahkan & 31 \\
Pengenalan tulisan (petunjuk/tanda) & tidak mengajak berbicara & 3 \\
& kadang-kadang & 43 \\
& tidak pernah & 29 \\
Membacakan buku cerita & sering & 28 \\
& tidak tentu & 72 \\
Mendongeng & seminggu beberapa kali & 14 \\
& setiap hari & 14 \\
Bermain dengan huruf, kata & tidak tentu & 68 \\
& setiap hari & 15 \\
& seminggu sekali sampai beberapa kali & 17 \\
Menggambar, mewarnai, menulis & tidak tentu & 49 \\
& setiap hari & 29 \\
Jumlah buku cerita anak & seminggu sekali sampai beberapa kali & 20 \\
& tidak tentu & 45 \\
& seminggu sekali sampai beberapa kali & 29 \\
& seminggu sekali & 26 \\
& $1-10$ buku & 81 \\
& $11-25$ buku & 18 \\
& $>25$ & 1 \\
& $1-25$ buku & 84 \\
& $26-50$ buku & 8 \\
& $>50$ & 8 \\
\hline & &
\end{tabular}

Berdasarkan Tabel 1 dan Tabel 2, disimpulkan bahwa mayoritas ibu memberikan stimulasi bahasa melalui percakapan, namun kadang-kadang saja ibu melakukan pengenalan tulisan. Bermain sambil belajar dalam bentuk aktivitas literasi anak bersama ibu seperti mendongeng, membaca buku cerita, dan bermain literasi belum menjadi kebiasaan rutin. Buku cerita anak yang dimiliki masih terbatas. Waktu anak lebih banyak dihabiskan untuk bermain tanpa arahan orangtua, sehingga permainan yang paling disukai adalah aktivitas motorik kasar dibandingkan aktivitas literasi.
Walaupun demikian kemampuan anak yang ingin dikembangkan ibu adalah kemampuan literasi, sehingga mayoritas stimulasi berupa bermain terkait literasi menggunakan media buku, kartu, gambar, dan alat tulis. Meskipun kegiatan membaca buku cerita belum rutin, pada saat dilakukan buku cerita yang dibacakan untuk anak adalah buku kartun, dongeng, dan majalah anak. Ternyata usaha mayoritas ibu ini masih belum berhasil meningkatkan minat dan ketertarikan anak sehingga merasa bosan dan malas. 
Tabel 2

Kegiatan Literasi di Rumah

\begin{tabular}{|c|c|c|}
\hline Kegiatan literasi ibu dan anak & Jawaban & $\%$ \\
\hline \multirow[t]{2}{*}{ Kegiatan anak untuk menghabiskan waktu } & bermain tanpa arahan orang tua & 77 \\
\hline & bermain dengan arahan orang tua & 23 \\
\hline \multirow[t]{3}{*}{ Permainan yang paling disukai anak } & permainan motorik kasar (di luar rumah) & 69 \\
\hline & permainan literasi (di dalam rumah) & 27 \\
\hline & permainan lainnya & 4 \\
\hline \multirow[t]{3}{*}{ Permainan literasi yang paling disukai anak } & permainan terkait huruf & 55 \\
\hline & permainan terkait gambar benda & 30 \\
\hline & belum dikenalkan huruf & 15 \\
\hline \multirow[t]{3}{*}{ Cara orang tua menstimulasi literasi anak } & permainan literasi & 54 \\
\hline & mengajarkan langsung & 31 \\
\hline & belum dikenalkan & 15 \\
\hline \multirow[t]{3}{*}{ Media stimulasi literasi } & buku, kartu, gambar, alat tulis & 69 \\
\hline & media elektronik & 21 \\
\hline & mainan & 10 \\
\hline \multirow[t]{3}{*}{ Buku cerita yang dibacakan untuk anak } & buku kartun, dongeng, majalah anak & 75 \\
\hline & buku cerita tokoh agama & 14 \\
\hline & tidak diceritakan & 6 \\
\hline Kemampuan anak yang ingin & kemampuan literasi & 47 \\
\hline \multirow[t]{2}{*}{ dikembangkan ibu } & kemampuan motorik & 24 \\
\hline & kemampuan sosialisasi & 29 \\
\hline \multirow[t]{3}{*}{ Masalah yang dihadapi ibu dalam stimulasi } & anak kurang tertarik, bosan, malas & 81 \\
\hline & lingkungan kurang mendukung & 8 \\
\hline & kesibukan ibu & 11 \\
\hline \multirow[t]{3}{*}{ Waktu stimulasi literasi anak } & malam & 45 \\
\hline & pagi-sore & 39 \\
\hline & tidak tentu & 16 \\
\hline
\end{tabular}

\section{Hasil Diskusi Kelompok Terfokus}

Dalam diskusi kelompok terfokus ditanyakan tiga pertanyaan sebagai bahan diskusi. Pertanyaan pertama bagaimana pendapat ibu-ibu tentang cara mengembangkan kemampuan literasi anak prasekolah, pertanyaan kedua bagaimana rutinitas anak dan adakah kegiatan mengenalkan tulisan dan alat tulis, terakhir ditanyaan apa saja yang menjadi harapan dan masalah selama ini. Hasil diskusi pertanyaan pertama menunjukkan bahwa secara umum para ibu memiliki pengetahuan tentang pentingnya menstimulasi kemampuan literasi anak prase- kolah. Tetapi para ibu belum memahami betul cara yang tepat melakukannya, sehingga yang mereka ketahui caranya lebih bersifat mengajar. Beberapa ibu mengalami kebingungan tentang apakah anak prasekolah boleh diajarkan membaca atau tidak, karena informasi yang beredar di masyarakat juga masih kontradiktif. Sebagian masyarakat mengatakan anak prasekolah belum boleh belajar membaca, sebagian lagi membolehkan. Setelah mendiskusikan pertanyaan kedua diketahui bahwa dalam aktivitas di rumah mayoritas orang tua sudah memiliki rutinitas sehari-hari yang teratur dalam hal bangun tidur, mandi, makan, pergi ke sekolah, 
bermain, belajar. Dalam rutinitas ini, lebih banyak ibu yang memperhatikan pengerjaan pekerjaan rumah sehingga anak lebih banyak bermain sendiri atau dengan teman/saudaranya. Masih sangat sedikit ibu yang menunjukkan usaha untuk memberikan arahan agar anak terlibat dalam aktivitas bermain sambil belajar. Ibu lebih senang bila anak tenang, asyik sendiri menonton TV atau main di luar rumah. Keterlibatan ibu dalam kegiatan bermain bersama anak masih sangat sedikit. Keterlibatan ibu lebih tampak saat anak mengerjakan pekerjaan rumah (PR) dari sekolah, mengajarkan IQRA, mengajarkan baca buku AISM atau ABACA (buku latihan mengeja). Harapan ibu terhadap anak rata-rata ingin anaknya cepat bisa membaca, menulis, berhitung, lebih mandiri, bersosialisasi. Masalah yang muncul berupa anak kurang fokus, mudah bosan, capek, malas selain itu ibu juga merasa kurang waktu dan tenaga.

Berdasarkan data diskusi kelompok disimpulkan bahwa masih banyak ibu yang menggunakan cara mengajar dan bukan bermain sambil belajar dalam melakukan stimulasi kemampuan literasi anak prasekolah, Selain itu mereka juga masih belum memanfaatkan interaksi natural dan melibatkan diri dalam kegiatan bermain anak sehari-hari untuk melakukan stimulasi. Keterlibatan ibu lebih karena membantu mengerjakan PR dari sekolah dan memberi pengajaran langsung baca tulis yang kurang menarik anak. Hal ini menimbulkan kurangnya minat anak untuk mengikuti stimulasi.

Dengan menganalisis kesimpulan data kuesioner dan diskusi kelompok terfokus, maka diketahui bahwa dibutuhkan metode stimulasi melalui bermain yang dapat menarik minat anak sehingga anak tidak merasa kesulitan untuk fokus, tidak mudah bosan dan capek, Anak membu- tuhkan stimulasi yang tidak dirasakan sebagai belajar tetapi sebagai bermain yang sesuai dengan kebutuhan perkembangannya. Untuk itu orangtua perlu memahami dan terampil menstimulasi kemampuan literasi anak prasekolah sambil bermain dengan menggunakan media yang menarik. Stimulasi yang bervariasi juga dibutuhkan untuk mengembangkan imajinasi anak melalui multimedia, multimetoda, dan multisensori yang merangsang semua modalitas belajar anak (audio, visual, dan kinestetik).

Untuk memenuhi kebutuhan di atas maka dirumuskan suatu model stimulasi yang berdasar pada pendekatan belajar multisensori, seperti terlihat pada Gambar 1 .

\section{Diskusi}

Model yang dirancang menggunakan pendekatan multisensori dengan tujuan agar potensi sensori auditif, visual maupun kinestetik semua difungsikan demi tercapainya perkembangan kemampuan literasi yang optimal. Selain itu pendekatan ini juga menawarkan kegiatan eksplorasi lingkungan secara aktif dan menyenangkan karena sesuai dengan kebutuhan perkembangan anak. Anak dapat memperoleh pengalaman membangun pengetahuannya dan mengembangkan sikap positif terhadap akitvitas literasi yang kemudian dibutuhkan untuk menanamkan minat membaca dan belajar. Secara konkrit model multisensori mengajarkan orang tua agar mengajak bicara saat makan, mandi, berpakaiarn kemudian membacakan buku cerita bergambar, merangsang anak menggambarkan kejadian dan tokoh dalam buku, juga bermain sambil mengajak berbicara, menyanyi, dan melakukan manipulasi alat tulis dan kertas atau melakukan permainan drama/ 


\section{RUHAENA}

bermain peran. Semua itu dapat disisipkan dan anak berinteraksi. dalam rutinitas harian selama orangtua

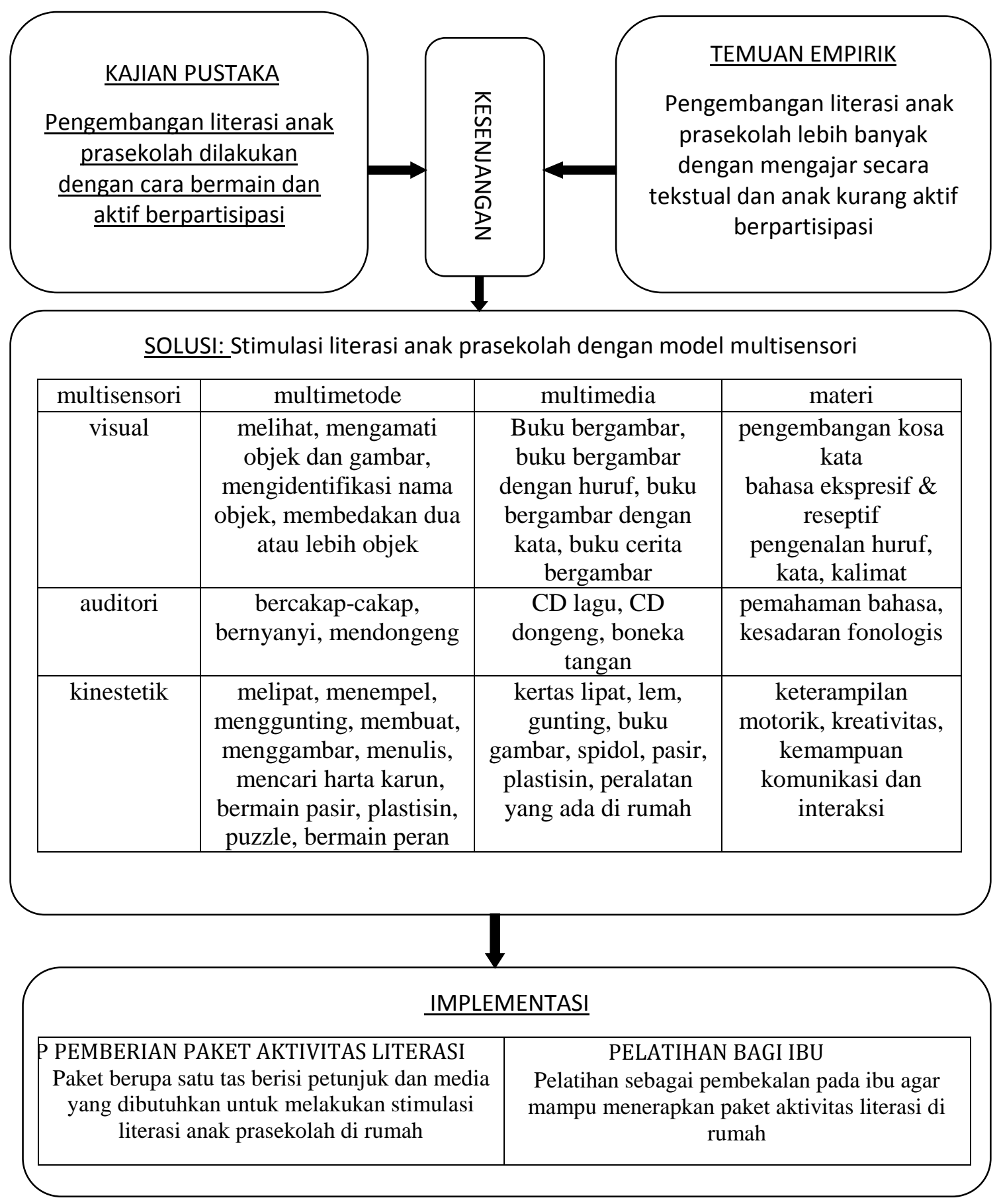

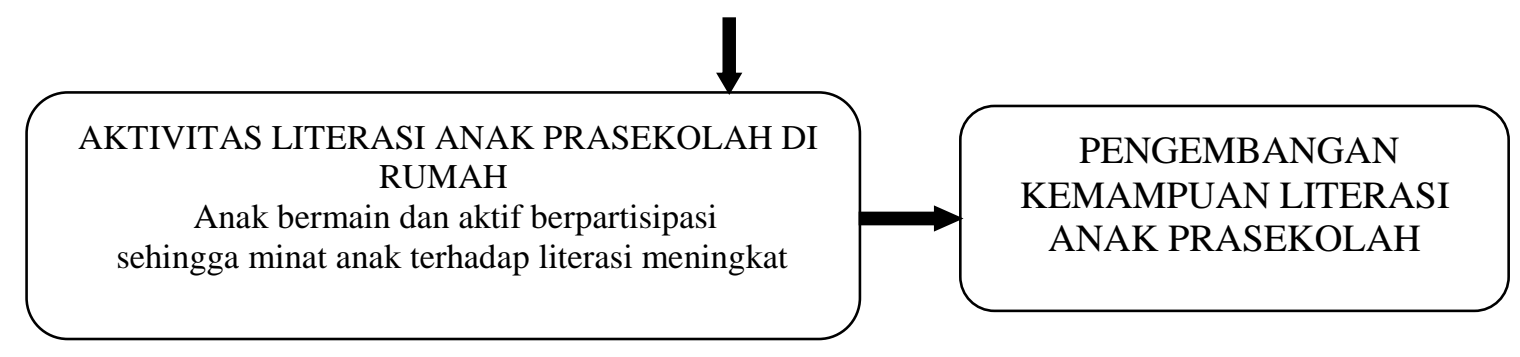


Gambar 1. Bagan model stimulasi yang berdasar pada pendekatan belajar multisensori

Dalam aplikasinya model ini menggunakan metode, media dan materi yang menjamin tercapainya rangsangan optimal terhadap semua sensorik yang dimiliki anak melalui aktivitas sehari-hari di rumah. Metode belajar bersifat aktif dan pertisipatif, anak lebih berperan sebagai subjek yang melakukan. Anak mendapatkan pengalaman belajar yang nyata dalam aplikasi. Berbagai media atau alat permainan edukatif termasuk buku digunakan untuk menunjang eksplorasi anak tentang berbagai objek di sekitarnya. Isi materi yang diberikan pada anak difokuskan pada kosa kata dan pengertian bahasa, kemampuan dasar membaca dan menulis, serta keterampilan fonologis.

Penggunaan model multisensori dalam aktivitas sehari-hari saat anak dan orangtua berinteraksi di rumah akan memberi struktur dan arah yang jelas bagi orangtua dalam merangsang perkembangan potensi anak sehingga tercipta budaya mendidik anak sejak dini sehingga menjadi pondasi yang kuat saat belajar di sekolah. Dengan rangsangan di rumah yang tepat, akan mendukung proses pembelajaran di sekolah sehingga terjadi kesinambungan pendidikan antara rumah dan sekolah. Metode stimulasi literasi anak prasekolah yang efektif adalah bersifat aktif dan partisipatif (Burgess, dkk., 2002; Levy dkk., 2006; Yaden, 1999) termasuk juga melakukan invented spelling (Martins \& Silva, 2006). Dalam aplikasinya, metode stimulasi multisensori memberi kesempatan anak untuk lebih aktif dan berpartisispasi. Metode ini merupakan cara yang menyenangkan dan sesuai dengan kebutuhan perkembangan anak karena mereka diajarkan dengan melihat, meraba, mendengar dan meng- ucapkan bunyi huruf serta mengasosiasikan bunyi huruf dengan sesuatu yang sangat mudah diingat yaitu cerita dan gerakan. Dengan metode ini anak dikenalkan pada baca tulis secara natural sebagai aktivitas yang biasanya dilakukan dalam konteks aktivitas sehari-hari, namun tetap juga merangsang keterampilan penting seperti pengetahuan huruf, kesadaran fenoemik, cara menulis huruf sehingga dengan keterampilan ini anak terbantu dalam baca-tulis (Lynch dkk., 2006). Green dkk. (2006) menyatakan bahwa beberapa aktivitas untuk meningkatkan kemampuan literasi dasar anak adalah membacakan buku dengan keras dan bersifat interaktif, meningkatkan pemahaman anak terhadap konsep tulisan, memberi anak kesempatan untuk mencorat-coret/menulis, mengenalkan dengan huruf, nama alfabetnya, bunyinya serta meningkatkan keterampilan fonologis.

Media yang digunakan dalam model ini dipilih alat permainan edukatif yang memiliki karekteristik tidak mengandung zat berbahaya dan tidak membahayakan bila dimanipulasi anak, mengandung pesan mendidik, bersifat menyenangkan, mudah didapatkan di lingkungan sekitar, tidak membutuhkan biaya mahal. Selain itu semua bentuk tulisan yang ada di sekitar rumah dapat dijadikan media seperti logo, label, nama jalan, dan nama toko (Neumann, Hood, \& Ford, 2012; 2013). Media ini dimanfaatkan dalam aktivitas anak di rumah saat bermain, berinteraksi, dan melakukan kegiatan rutin sehari-hari bersama orangtua atau orang dewasa lainnya. Beberapa contoh media yang akan digunakan adalah buku cerita anak bergambar, boneka, mainan berbentuk huruf, kartu bertuliskan kata, 
papan tulis, pensil dan spidol, buku mewarnai atau aktivitas, benda-benda mainan anak. Maskot dari media belajar literasi dasar ini berupa paket buku cerita dan tokoh boneka dan benda-benda yang ada dalam cerita. Paket ini dipakai untuk mendukung tercapainya pengalaman membaca buku yang menyenangkan dan menarik.

Materi yang dikenalkan pada anak mencakup kemampuan bahasa reseptif dan ekspresif (Dickenson \& Mc Cabe, 2001), pengetahuan tulisan, cara membaca (Weigel dkk., 2006), cara menulis (Graham dkk., 2000), kesadaran fonemik (Byrne dkk., 2000, Hetcher, 2006; dan Hoff, 2005). Materi ini merupakan bahan yang dikenalkan tanpa harus mengejar target tetapi lebih bersifat memfokuskan orangtua dalam melakukan stimulasi agar mendapat arah yang jelas dan anak memiliki kemampuan dan keterampilan yang mendukungnya untuk menguasai keterampilan lebih lanjut yang lebih sulit.

Aktivitas sehari-hari di rumah merupakan konteks yang dipilih dengan alasan mengoptimalkan peran orangtua sebagai orang yang signifikan dan guru pertama bagi anak. Keterlibatan orangtua yang besar bernilai strategis mengingat orangtua pemberi kontribusi penting bagi kesuksesan anak dalam belajar baca tulis (Paratore dalam Reutzel dkk, 2006). Pola asuh orangtua dan lingkungan rumah berperan penting dalam perkembangan kemampuan baca tulis (Mellhuish dkk., 2008). Lingkungan rumah yang responsif terhadap anak meningkatkan kemampuan bahasa (reseptif dan ekspresif) dan kemampuan baca tulis (Roberts dkk., 2005). Anak belajar lebih baik dalam konteks relasi orangtua-anak (Mullis dkk., 2004). Begitu pula perkembangan baca tulis bahasa Cina yang sulit, dapat dikuasai oleh anak karena peran orangtua ( $\mathrm{Li} \&$
Rao, 2000). Pengembangan baca tulis lebih direkomendasikan melibatkan orangtua (Reese, 2010), beberapa program intervensi untuk meningkatkan pengetahuan dan keterampilan orangtua dalam merangsang perkembangan baca tulis anak terbukti efektif (Cronan dkk., 1996; Saint-Laurant \& Giasson, 2005; Rasinski, 2005; Reutzel dkk, 2006). Keterampilan yang dibutuhkan orangtua saat membantu anaknya belajar baca tulis adalah metalingual utterance yaitu mengarahkan anak untuk memperhatikan bahasa yang dipakai (Deckner dkk., 2006), verbal scaffolding yaitu memberikan penjelasan konsep objek (Dieterich $\mathrm{dkk}, 2006)$

Aktivitas literasi anak bersama orang tua dapat menjadi stimulasi penting dalam kemampuan literasi anak prasekolah dijelaskan dengan teori sosio-kultural Vygotsky. Proses pencapaian kemampuan bahasa dan literasi anak prasekolah dilihat sebagai hasil interaksi sosial. Artinya kemampuan ini dicapai karena terjadi interaksi sosial dengan hadir seseorang yang memiliki kemampuan, pengetahuan lebih dari anak seperti orang tua atau pengasuh yang memberikan panduan secara verbal untuk mengembangkan kemampuan aktual anak menjadi lebih baik (zona of proximal). Orang dewasa menstrukturkan aktivitas untuk memungkinkan anak terlibat dalam perilaku yang lebih kompleks dari yang bisa mereka lakukan sendiri. Dalam aktivitas ini tercipta kesempatan anak untuk belajar melalui imitasi, instruksi dari orang tua, serta kooperatif. Orang tua menstrukturkan aktivitas literasi anak dan mengajak anak untuk berpartisipasi aktif dalam interaksi sosial terkait baca tulis seperti membaca buku, menulis pesan, dan memilih buku yang menarik untuk dibeli.

Melalui interaksi anak dan orang lain dalam kesehariannya, intelektual anak 
berproses untuk mengembangkan kemampuan melakukan tugas dan menyelesaikan masalah sesuai dengan kekhususan lingkungan sekitar mereka. Orang tua seringkali tidak menyadari teknik memberi instruksi, tetapi praktik membesarkan anak yang dipengaruhi nilai-nilai budaya biasanya sesuai dengan bagaimana anak akan hidup di masa dewasanya (Bjorklund, 2005). Perspektif sosiokultural ini menekankan bahwa perkembangan dipandu oleh interaksi orang dewasa dengan anak dalam konteks kultural yang menentukan bagaimana, dimana dan kapan interaksi ini berlangsung. Menurutnya perkembangan kognitif berlangsung dalam situasi di mana anak memecahkan masalah dengan panduan orang dewasa. Dalam hal ini perkembangan kognitif berlangsung melalui kolaborasi antara anggota suatu generasi dengan anggota lainnya.

Proses belajar dimediasi oleh bahasa, oleh karena itu kemampuan literasi selalu diawali oleh perkembangan bahasa. Orang dewasa memberikan pertanyaan, ungkapan/pernyataan, dan memberi dukungan sehingga terjadi proses belajar dan kemampuan anak kemudian meningkat. Dengan demikian dalam belajar literasi terjadi proses dalam dua tataran yaitu tataran sosial dan individual. Tataran sosial merupakan proses dimana terjadi interaksi dan komunikasi dari orangtua kepada anak. Tataran individual terjadi saat anak memproses informasi yang disampaikan kepadanya dalam kognitif, yang membuatnya mampu mengembangkan kemampuan yang dimiliki, dalam hal ini kemampuan literasi.

Tinjauan sosial-kultural menjelaskan perolehan kemampuan bahasa dan literasi anak prasekolah terjadi dalam konteks kehidupan sehari-hari yang bermakna melalui keterlibatan aktif dalam aktivitas yang nyata dalam lingkungan mikrosistem yaitu keluarga. Aktivitas ini diarahkan oleh orang dewasa di rumah terutama orang tua sehingga tercipta interaksi sosial yang merangsang potensi kognitif, bahasa, dan literasi anak prasekolah. Melalui percakapan dengan anak orang tua meningkatkan kemampuan pengucapan kata dan menambah kosakata anak kemudian mengembangkan keterampilan berkomunikasi. Kemampuan bahasa ini mendasari kemampuan membaca, semakin kaya kosakata yang dimiliki semakin mudah memaknai tulisan dan semakin cepat belajar membaca. Melalui kegiatan bermain terkait buku dan tulisan seperti bermain huruf, kata dan membaca buku anak dikenalkan pada pengetahuan tulisan serta tata cara membaca. Bentuk aktivitas dan interaksi yang bervariasi merupakan strategi yang dapat disesuaikan dengan kondisi dan kebutuhan unik masing-masing anak.

\section{Kesimpulan}

Temuan empirik menunjukkan bahwa pengembangan kemampuan literasi anak prasekolah dilakukan dengan cara mengajar yang kurang aktif partisipatif, dan menimbulkan masalah anak kurang tertarik dan kurang berminat terhadap stimulasi literasi. Permasalahan ini membutuhkan solusi yang tepat. Model multisensori yang dirumuskan secara teoretis diharapkan dapat menjadi solusi permasalahan pengembangan literasi anak prasekolah. Stimulasi dengan multisensori mengoptimalkan semua sensori anak dan aktivitas literasi sambil bermain menjadi kekuatan dan kelebihan untuk menarik minat anak. Oleh karena itu penelitian lanjutan untuk menguji efektivitas model multisensori dalam mengembangkan kemampuan literasi anak prasekolah menjadi penting untuk dilakukan. 


\section{Kepustakaan}

Aram, D., Most, T., \& Mayafit, H. (2006) Contributions of mother-child storybook telling and joint writing to literacy development in kindergartners with hearing loss. Language, Speech, and Hearing Services in Schools, 37, 209.

Burgess, S. R., Hecht, A. S., \& Lonigan, C. J. (2002). Relation of the home literacy environtment (HLE) to the development of reading-related abilities: a one-year longitudinal study. Reading Research Quarterly, 37(4), 408-426.

Brooker, L. (2011). Taking children seriously: an alternative agenda for research? Journal of Early Childhood Research, 9(2), 137-149.

DeBruin-Parecki, A. (2009). Establishing a family literacy program with a focus on interactive reading: The role of research and accountability. Early Childhood Education Journal, 36(5), 385392.

Dickinson, D. K., \& McCabe, A. (2001). Bringing it all together: The multiple origins, skills, and environmental supports of early literacy. Learning Disabilities Research and Practice, 16(4), 186-202.

Dieterich, S. E., Assel, M. A., Swank, P., Smith, K. E., \& Landry, S. H. (2006) The impact of early maternal verbal scaffolding and child language abilities on later decoding and reading comprehension skills. Journal of School Psychology, 43, 481-494.

Evans, M. A., \& Shaw, D. (2000). Home literacy and their influence on early literacy skills. Canadian Journal of Experimental Psychology, 54(2), 65-75.

Farkas, R. D. (2003). Effects of traditional versus learning-styles instructional methods on middle school students. The Journal of Educational Research, 97(1), 42-51.

Fisher, R. (2010) Young writers' construction of agency. Journal of Early Childhood Literacy, 10, 410-429.

Graham, S., Harris, K. R., \& Fink, B. (2000) Is handwriting causally related to learning to write? Treatment of handwriting problems in beginning writers. Journal of educational psychology, 92, 620.

Green, S. D., \& Peterson, R. (2006). Language and literacy promotion in early childhood settings: A survey of center-based practices. Early Childhood Research and Practice, 8(1), 1-18.

Hetcher, P. J., Goetz, K., Snowling M. J., Hulme C., Gibbs S. \& Smith G. (2006). Evidence for the Effectiveness of the Early Literacy Support Programme. British Journal of Education Psychology, 76, 351-367.

Hoff, E. (2005). Language Development. Belmont, CA: Wadsworth.

Kendrick, M., \& McKay, R. (2004). Drawings as an alternative way of understanding young children's constructions of literacy. Journal of Early Childhood Literacy, 4(1), 109-128.

Levy, B. A., Gong, Z., Hessels, S., Evans, M. A., \& Jared, D. (2006) Understanding print: Early reading development and the contributions of home literacy experiences. Journal of Experimental Child Psychology, 93, 63-93.

Li, H., \& Rao, N. (2000). Parental influences on Chinese literacy development: a comparison of preschoolers in Beijing, Hongkong, and Singapore. International Journal of Behavioral Development, 24(1), 82-90. 
Maal, N. (2004). Learning via multisensory engagement. Association Management, $56,11-61$.

Martins, M. A., \& Silva, C. (2006). The Impact of Invented Spelling on Phonemic Awareness. Journal of Learning and Instruction, 16, 41- 56

Mullis, I., Martin, M., Kennedy, A., \& Foy, P. (2007) Progress in international reading literacy study. Pirls 2006 report. In: Lynch School of Education, Boston College, Chestnut Hill, MA: TIMMS \& PIRLS International Study Centre. International Association for the Evaluation of Educational Achievement (IEA).

Mullis, R. L., Mullis, A. K., Cornille, T. A., Ritchson, A. D. \& Sullender, M. S. (2004). Early literacy outcomes and parent involvement. Tallahassee, Fl: Florida State University.

Neumann, M. M., Hood, M., \& Ford, R. M. (2013). Using environmental print to enhance emergent literacy and print motivation. Reading and Writing, 26(5), 771-793.

Neumann, M. M., Hood, M., \& Ford, R. M. (2012). Mother-child joint writing in an environmental print setting: Relations with emergent literacy. Early Child Development and Care, 182(10), 1349-1369.

Orton, S. T., \& Gillingham, A. (2000). Orton Gilingham multisensory phonics programs. Diunduh dari: www.gophonics. com. Maret 2010.

Raikes, H., Alexander Pan, B., Luze, G., Tamis-LeMonda, C. S., Brooks-Gunn, J., Constantine, J., Banks Tarullo, L., Abigail Raikes, H., \& Rodriguez, E. T. (2006) Mother-child bookreading in low-income families: Correlates and outcomes during the first three years of life. Child Development, 77, 924-953.
Rasinski, T., \& Stevenson, B. (2005). The effects of fast start reading: A fluencybased home involvement reading program, on the reading achievement of beginning readers. Reading Psychology, 26, 109-125. http:// dx.doi.org/10.1080/ 02702710590930483

Reese, E., Sparks, A., \& Leyva, D. (2010). A review of parent intervention for preschool children's language and emergent literacy. Journal of Early Childhood Literacy, 10(1), 97-117. http:// dx.doi.org/10.1177/1468798409356987

Reutzel, D. R., Fawson, P. C., \& Smith, J. A. (2006). Words to go!: Evaluating the first-grade parent involment program for 'making' words at home. Reading Reasearch and Instructions, 45, 119-159.

Roskos, K. A., Christie, J. F., Widman, S., \& Holding, A. (2010) Three decades in: Priming for meta-analysis in playliteracy research. Journal of Early Childhood Literacy, 10, 55-96.

Ruhaena, L. (2008) Pengaruh Metode Pembelajaran Jolly Phonics terhadap Kemampuan Baca-tulis Permulaan Bahasa Indonesia dan Bahasa Inggris pada Anak Prasekolah. Jurnal Penelitian Humaniora, 9(2), 190-204.

Ruhaena, L., Kumara, A., Adiyanti, M. G., \& Helmi, A. F. (2014). Home literacy activities and early literacy skills achievement in indonesian family context. Paper presented at the Asian Association of Indegenous and Cultural Psychology Conference on Stress, Health, Well Being: Indegenous, Social and Cultural Perspective, Surakarta, Indonesia.

Senechal, M., \& LeFreve, J. (2002). Parental Involvment in the development of children's reading skill: a five-year longitudinal study. Child Development, $73,445-460$ 


\section{RUHAENA}

Stephenson, K. A., Parrila, R. K., Georgiou, G. K., \& Kirby, J. R. (2008) Effects of home literacy, parents' beliefs, and children's task-focused behavior on emergent literacy and word reading skills. Scientific Studies of Reading, 12, 24-50.

Saint-Saint-Laurant, L., \& Giasson, J. (2005) Effects of family literacy adapting parental intervention to first graders' evolution of reading and writing abilities. Journal of Early Childhood Literacy, 5(3), 253-278.
Tiene, D. (2000). Sensor mode and information traditional examining: The effects of timing on multisensory processing. Kent State University International Journal of Instruction Media, 27(2), 56-57.

Weigel, D. J., Martin S. S., \& Bennett, K. K. (2006). Mother's literacy beliefs: connections with the home literacy environment and pre-school chldren's literacy development. Journal of Early Childhood Literacy, 6(2), 191-211. http:// dx.doi.org/10.1177/1468798406066444 